\title{
Estimating the cost-effectiveness profile of a universal vaccination programme with a nine-valent HPV vaccine in Austria
}

\author{
L. Boiron ${ }^{1}$, E. Joura ${ }^{2}$, N. Largeron ${ }^{1}$, B. Prager ${ }^{3}$ and M. Uhart ${ }^{*}$
}

\begin{abstract}
Background: HPV is a major cancer-causing factor in both sexes in the cervix, vulva, vagina, anus, penis, oropharynx as well as the causal factor in other diseases such as genital warts and recurrent respiratory papillomatis. In the context of the arrival of a nonavalent HPV vaccine (6/11/16/18/31/33/45/52/58), this analysis aims to estimate the public health impact and the incremental cost-effectiveness of a universal (girls and boys) vaccination program with a nonavalent HPV vaccine as compared to the current universal vaccination program with a quadrivalent HPV vaccine (6/11/16/18), in Austria.

Method: A dynamic transmission model including a wide range of health and cost outcomes related to cervical, anal, vulvar, vaginal diseases and genital warts was calibrated to Austrian epidemiological data. The clinical impact due to the 5 new types was included for cervical and anal diseases outcomes only. In the base case, a two-dose schedule, lifelong vaccine type-specific protection and a vaccination coverage rate of $60 \%$ and $40 \%$ for girls and boys respectively for the 9-year old cohorts were assumed. A cost-effectiveness threshold of $€ 30,000 / Q A L Y$-gained was considered.
\end{abstract}

Results: Universal vaccination with the nonavalent vaccine was shown to reduce the incidence of HPV16/18/31/ $33 / 45 / 52 / 58$-related cervical cancer by $92 \%$, the related CIN2/3 cases by $96 \%$ and anal cancer by $83 \%$ and $76 \%$ respectively in females and males after 100 years, relative to $75 \%, 76 \%, 80 \%$ and $74 \%$ with the quadrivalent vaccine, respectively. Furthermore, the nonavalent vaccine was projected to prevent an additional 14,893 cases of CIN2/3 and 2544 cases of cervical cancer, over 100 years. Depending on the vaccine price, the strategy was shown to be from cost-saving to cost-effective.

Conclusion: The present evaluation showed that vaccinating $60 \%$ of girls and $40 \%$ of boys aged 9 in Austria with a 9 -valent vaccine will substantially reduce the incidence of cervical cancer, CIN and anal cancer compared to the existing strategy. The vaccination strategies performed with the 9-valent vaccine in the current study were all found to be cost-effective compared to the current quadrivalent vaccination strategy by considering a cost-effectiveness threshold of 30,000€/QALY gained.

Keywords: Cost-effectiveness, Austria, HPV, Cervical cancer, Vaccination

\footnotetext{
* Correspondence: muhart@spmsd.com

${ }^{1}$ Sanofi Pasteur MSD, 162 avenue Jean Jaurès CS 50712 69367, Lyon Cedex

07, France

Full list of author information is available at the end of the article
} 


\section{Background}

The Human Papillomavirus (HPV) is a virus that infects squamous epithelia [1]. HPV is the most common sexually transmitted infection and can be passed on through genital contact or by skin-to-skin contact [2, 3]. HPV infections are most of the time transient and cleared up within a few months after acquisition. However, in some cases, $\mathrm{HPV}$ infection can persist and progress to non-cancerous or cancerous lesions [4]. HPV is recognized as a major cancer causing factor in both sexes: in the cervix, vulva, vagina for females, in the penis for males and in the anus and oropharynx in both sexes, as well as the causal factor of other diseases such as genital warts and recurrent respiratory papillomatis (mainly due to HPV 6 and 11). The HPV-related burden is substantial for individuals, healthcare systems and society as a whole. Cervical cancer is the second most common female cancer in women aged 15 to 44 in the European Union, and nearly all cases can be attributed to HPV infection $[5,6]$. In Europe, it is estimated that about 34 thousands new cervical cancer cases are diagnosed and 13 thousands new cervical cancer deaths occurred in 2012 [4]. Two preventative strategies are used in combination to avert cervical cancer: the screening (secondary prevention) and the HPV vaccination (primary prevention). The screening allows to detect - and then treat - precancerous lesions before they evolve into cancer. The screening is very effective but is only implemented for cervical cancer prevention. No screening exists for other HPV cancers. In Austria, the cytology screening is opportunistic: Participation depends on the individual decision.

There are currently two commercially available vaccines in Europe: the quadrivalent (HPV 6, 11, 16, 18) vaccine Gardasil $^{\circledR}$ and the bivalent (HPV 16, 18) vaccine Cervarix ${ }^{\odot}$. A new generation of vaccine, the nona-valent vaccine, has been recently approved by the EMA $[7,8]$. This new vaccine will expand coverage against 5 more oncogenic types (HPV 31, 33, 45, 52, 58) in addition to the 4 original types included in Gardasil ${ }^{\circ}$. Indeed, the nonavalent vaccine has the potential to prevent approximately $90 \%$ of cervical, vulvar, vaginal and anal cancers and $80 \%$ of precancerous lesions $[9,10]$.

Since 2008, HPV vaccine programmes have been implemented in most EU countries in girls. Austria is the first country in Europe having implemented a HPV vaccination programme for girls and boys in 2014. Outside Europe, a universal vaccination programme is implemented in the US, some Canadian provinces, in Australia and in Israel. Economic and social considerations associated with male vaccination have been widely discussed [11-15]. Overall, extension of the vaccination program to males is mainly justified by (i) epidemiological reasons: the burden of HPV related diseases in boys and men is substantial, (ii) equity reasons: men who have sex with men do not benefit from the herd immunity conferred by girls' vaccination, and (iii) efficiency reasons: herd protection can only be achieved if the vaccination program has a sufficiently coverage rate. Vaccinating boys and girls is a way to improve the coverage and to stop the spread of the associated diseases [16, 17].

In the context of the recent availability of the nonavalent HPV vaccine, and considering the heavy HPVrelated economic burden imposed on healthcare systems and society, it is important to inform policy and decision makers on the expected public health impact and costeffectiveness of the new vaccine compared to existing preventive strategies.

In Austria as well as other countries in Europe, numerous are the published studies assessing the costeffectiveness of HPV vaccines [18-21]. So far, however, there has not been any analysis assessing the costeffectiveness of the nonavalent vaccine in Europe. On the contrary, the cost-effectiveness of nonavalent HPV vaccination was assessed in the United States, through 3 models which were presented during the Advisory Committee on Immunization Practices (ACIP) meeting in February 2015 [22-25]. Results were consistent across the three different models: universal vaccination with the nonavalent vaccine priced moderately was estimated to be cost-saving compared to universal vaccination with Gardasil $^{\circledR}$, or at least very cost-effective at higher prices.

The present analysis aimed to assess the incremental public health impact and to provide realistic costeffectiveness estimates of a girls and boys (universal) vaccination program with the nonavalent $\mathrm{HPV}$ vaccine compared to the current universal quadrivalent HPV vaccine, in Austria, both performed in conjunction with the current screening strategy.

\section{Methods \\ Mathematical model}

A previously published US model, simulating the natural history of genotypes 6, 11, 16, 18 HPV-infections and estimating the cost associated with HPV-related diseases, has been extended to account for infections and diseases attributable to HPV genotypes 31, 33, 45, 52, 58 and adapted to Austria in order to estimate the cost-effectiveness of a 9-valent vaccine against Human Papillomavirus [26-29].

The model consists of three connected modules: (1) a demographic model that defines the demographic characteristics of the population and describes how persons enter, age within, and exit the model; (2) an epidemiologic module that simulates HPV transmission and the occurrence of HPV-related diseases; (3) an economic model that estimates costs and quality of life associated with the screening, vaccination and management of the 
disease for each prevention strategy. A detailed description of the model was presented in Elbasha et al. [29].

The epidemiologic module is constituted of 16 separate and independent models to take into account the many HPV-types and many diseases related to. Whereas HPV 6, 11, 16 and 18 are modelled separately, the 5 additional types are combined into a single set of compartments. Indeed, the epidemiologic module includes one HPV6-specific model (RRP, genital warts and CIN1) one HPV11-specific model (RPP and genital warts), one separate model for each disease related to HPV 16 or HPV18 (cervical precancerous lesion and cancer, vulvar precancerous lesion and cancer, vagina precancerous lesions and cancer, anal precancerous lesion and cancer, penile precancerous lesions and cancer, and head and neck cancer). Last, the 5 additional types (HPV31, 33, 45, 52 and 58) have been merged as one "super-type" for which one separate model has been created for cervical diseases and another one for anal diseases. All together, the model accounts for the transmission dynamics of nine HPV types: $16,18,6,11,31,33,45,52$, and 58 , and simulate the occurrence of genital warts; RRP; pre-cancers such as cervical intraepithelial neoplasia (CIN); cervical, vulvar, vaginal, penile, anal, and head/neck cancers related to these HPV types. The current analysis assumes only cervical cancers and pre-cancers and anal cancers have significant contributions from the 5 additional types. The contribution of the types 33/33/45/52/58 to the burden of other diseases (vaginal, vulvar, penile, head and neck cancers, genital warts, and RRP) was not modeled.

Different strategies were analysed and compared:

- 9-valent vaccine for girls and boys associated with current cervical cancer screening;

- 4-valent vaccine for girls and boys associated with current cervical cancer screening.

\section{Input parameters}

\section{Demographics \& sexual behavior}

Population data was retrieved from Statistics Austria. The total population in Austria at the beginning of the year 2014 was estimated to be $8,507,786$ people [30]. A constant population size was assumed. Data on sexual behaviour in Austria were scarce so the results from the UK NATSAL-3 study were used as they were deemed to be applicable to the Austrian setting according to expert opinion [31].

\section{Natural history of disease and treatment patterns}

The progression from infection to disease follows a similar natural history structure as the initial US model, previously described and reported [29]. As transmission rates are not directly observable, calibration techniques were used to obtain the best set of parameters.
The female population receiving hysterectomy over the course of 1 year by age group was first estimated from the incidence rates of hysterectomy by age reported by the German Statistical Office [32]. Then, rates have been adjusted to the number of hysterectomy cases in Austria reported by Statistics Austria (2013) [33].

\section{Screening}

The annual cervical cancer screening rates were extracted from the report by Zechmeister [19]. The percent of females receiving gynecological cancer screening tests at least once every 3 years was set to $47 \%$ [34] and the percentage of women receiving a follow-up screening test after abnormal Papanicolaou test (Pap test or Pap smear) was estimated at $90 \%$ according to expert opinion. Since no screening program for vulvar and vaginal cancer screening practice exists, the percentage of females receiving regular vaginal cancer screening was set to $0 \%$.

\section{Vaccination strategy}

The current vaccination program in Austria is for girls and boys to get vaccinated at their $9^{\text {th }}$ year of age, with vaccination coverage rates assumed of $60 \%$ for girls and $40 \%$ for boys [35]. The vaccination consists of a two-dose schedule assuming an adherence rate (proportion receiving the $2^{\text {nd }}$ dose) of $100 \%$. It was deemed that universal vaccination with the nonavalent vaccine would have the same characteristics (coverage and adherence) as the current vaccination for girls and boys and that performance does not differ between the two vaccines.

\section{Vaccine properties}

The prophylactic efficacy of the vaccine or vaccineconferred degree of protection was based on clinical trial data (Table 1) [36-41]. The duration of protection against HPV genotypes 6/11/16/18/31/33/45/52/58 was assumed to be lifelong. This assumption relies on the immunogenicity and effectiveness data of Gardasil ${ }^{\circ}$ [42-44] that have demonstrated an efficacy up to ten years and the mathematical modelling of antibody decay following vaccination. Indeed, the long term duration of protection afforded by HPV vaccination was modelled on data obtained from phase II study involving a monovalent HPV 16 vaccine. The predicted persistence of anti-HPV levels over time was estimated using two mixed effects models. The first was a conventional model of antibody decay and the second was a modified model that accounts for long-lived immune memory. Using the antibody decay model, it was estimated that following administration of a three-dose regimen of HPV-16 vaccine [45] in women aged 16-23 years, antiHPV-16 levels will remain above those induced naturally by HPV-16 infection for 12 years, and above detectable levels for 32 years in $50 \%$ of vaccinees. With the modified model, 
Table 1 Summary table on vaccine efficacy

\begin{tabular}{|c|c|c|c|}
\hline Vaccine assumptions & HPV 16 & HPV 18 & HPV $31,33,45,52$ and 58 \\
\hline \multicolumn{4}{|l|}{ Cervical cancer } \\
\hline \multicolumn{4}{|l|}{ Vaccine efficacy for preventing cervical HPV16/18/31/33/45/52/58 infections: } \\
\hline - Male & 0.411 & 0.621 & 0.411 \\
\hline - Female & 0.76 & 0.963 & 0.76 \\
\hline $\begin{array}{l}\text { Degree of protection of the vaccine against cervical HPV16/18 } \\
\text { infections becoming persistent }\end{array}$ & 0.988 & 0.984 & 0.988 \\
\hline Degree of protection of the vaccine against HPV16/18 -related CIN & 0.979 & 1 & 0.979 \\
\hline \multicolumn{4}{|l|}{ Vaginal and vulvar cancers } \\
\hline \multicolumn{4}{|l|}{ Vaccine efficacy for preventing vaginal/vulvar HPV16/18 infections: } \\
\hline - Male & 0.411 & 0.621 & \\
\hline - Female ${ }^{b}$ & 0.76 & 0.963 & \\
\hline $\begin{array}{l}\text { Degree of protection of the vaccine against vaginal/vulvar HPV16/18 } \\
\text { infections becoming persistent }\end{array}$ & 0.988 & 0.984 & \\
\hline Degree of protection of the vaccine against HPV16/18-related NaIN/VIN & 1 & 1 & \\
\hline \multicolumn{4}{|l|}{ Anal cancers } \\
\hline \multicolumn{4}{|l|}{ Vaccine efficacy for preventing anal infections } \\
\hline - Male & 0.411 & 0.621 & 0.621 \\
\hline - Female & 0.76 & 0.963 & 0.963 \\
\hline \multicolumn{4}{|l|}{$\begin{array}{l}\text { Degree of protection of the vaccine against anal infections } \\
\text { becoming persistent }\end{array}$} \\
\hline - Male & 0.787 & 0.96 & 0.96 \\
\hline - Female & 0.988 & 0.984 & 0.984 \\
\hline $\begin{array}{l}\text { Degree of protection of the vaccine against HPV16/18 -related } \\
\text { AIN neoplasia }\end{array}$ & 0 & 0 & 0 \\
\hline \multicolumn{4}{|l|}{ Penile and H\&N cancers } \\
\hline \multicolumn{4}{|l|}{ Vaccine efficacy for preventing penile and $\mathrm{H} \& \mathrm{~N}$ infections } \\
\hline - Male & 0.411 & 0.621 & \\
\hline - Female ${ }^{b}$ & 0.76 & 0.963 & \\
\hline \multicolumn{4}{|l|}{$\begin{array}{l}\text { Degree of protection of the vaccine against penile and } H \& N \\
\text { infections becoming persistent }\end{array}$} \\
\hline - Male & 0.787 & 0.96 & \\
\hline - Female ${ }^{b}$ & 0.988 & 0.984 & \\
\hline $\begin{array}{l}\text { Degree of protection of the vaccine against HPV16/18 -related } \\
\text { PIN and H\&N neoplasia }\end{array}$ & 0 & 0 & \\
\hline
\end{tabular}

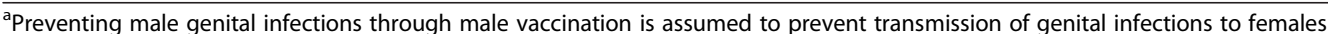

breventing female genital infections through vaccination is assumed to prevent transmission of genital infections to males

Source: Giuliano et al. (2011) [38] and Elbasha and Dasbach (2010) [28]

which fitted the data better $(p<0.001)$, it was estimated that near life-long persistence of anti-HPV-16 following vaccination is expected in $99 \%$ of subjects. Given that each of the nine VLPs contained in Gardasil 9 are the relevant L1 protein and all are therefore expected to elicit an immune response by the same mechanism, there is currently no evidence to suggest that similar long term duration of protection would not apply to HPV types 6, 11, 18, 31, 33, 45, 52 and 58. Duration of protection was also tested in sensitivity analyses with lower duration of 20 years.
As the model includes degree of protection against infection and degree of protection against disease arising from a breakthrough infection, it considers different efficacy values against infection and against disease. In the model, it is further assumed that these "breakthrough" infections are transmissible. The efficacy against anal, head and neck, penile and RRP diseases was assumed to be conferred through protection against infection only.

Values on vaccine efficacy were not available specifically for the Austrian population. The US model has 
been already shown to be transferable to other countries [46]. In line with the current Austrian recommendation, a two-dose regimen was considered in the model for quadrivalent vaccine and also for 9-valent vaccine.

As the duration and strength of effectiveness of cross protection is uncertain [47-51] and has still to be demonstrated as highlighted in the recent WHO guidance on cervical cancer, no cross-protection was assumed in the base case [52].

Vaccine efficacy parameters considered in the model are presented in the Table 1.

\section{Perspective}

In Austria, HPV vaccination is delivered through a national public programme and vaccine purchase is realized with public tenders. All the costs are from the perspective of the payer.

\section{Cost of vaccination}

In Austria, the manufacturer's price of the quadrivalent vaccine is $110 €[21]$. The price of the nonavalent vaccine was not available in Austria since the product is not yet marketed. A broad range of prices for the nonavalent vaccine was assessed, from $110 €$ up to the maximum cost-effective price. A theoretical price of $135 €$ for the nonavalent vaccine was assumed in the base case and for the sensitivity analysis. It corresponds to the average of the price in the private sector $\left(147.91 €^{* 1}\right)$ and the CDC price $\left(121.76 €^{* 1}\right)$ of the nonavalent vaccine currently observed in the US [53]. The administration cost per dose was set at $12 €[18]$.

\section{Cost per episode of care}

The costs per episode of care of each HPV-related disease, defined as the cost of management from diagnosis to resolution of the case are reported in the Table 2. Costs were retrieved from Hillemanns et al. [54], Hampl et al. [55],

Table 2 Summary table on costs and utilities for HPV-related disease

\begin{tabular}{|c|c|c|c|}
\hline Parameter & Gender & Inflated values (€2014) & Utility $[27,58,59]$ \\
\hline - CIN 1 & Female & $377 €[54]$ & 0.91 \\
\hline - CIN 2 & Female & $377 €[54]$ & 0.87 \\
\hline - CIN 3 and CIS & Female & $1681 €[54]$ & 0.87 \\
\hline - Cervical cancer, local disease ${ }^{a}$ & Female & $19,151 €[19]$ & 0.76 \\
\hline - Cervical cancer, regional disease ${ }^{a}$ & Female & $31,978 €[19]$ & 0.67 \\
\hline - Cervical cancer, distant disease ${ }^{a}$ & Female & $32,651 €[19]$ & 0.48 \\
\hline - ValN 2 & Female & $936 €[55]$ & 0.87 \\
\hline - ValN 3, CIS & Female & $2766 €[55]$ & 0.87 \\
\hline - Vaginal cancer, local disease ${ }^{a}$ & Female & $16,661 €[19]$ & 0.76 \\
\hline - Vaginal cancer, regional disease ${ }^{a}$ & Female & $27,820 €[19]$ & 0.67 \\
\hline - Vaginal cancer, distant disease ${ }^{a}$ & Female & $28,406 €[19]$ & 0.48 \\
\hline - Vulvar cancer, local disease ${ }^{a}$ & Female & $16,661 €[19]$ & 0.76 \\
\hline - Vulvar cancer, regional disease ${ }^{a}$ & Female & $27,820 €[19]$ & 0.67 \\
\hline - Vulvar cancer, distant disease ${ }^{a}$ & Female & $28,406 €[19]$ & 0.48 \\
\hline - Penile cancer, local disease ${ }^{a}$ & Male & $13,597 €[19]$ & 0.76 \\
\hline - Penile cancer, regional disease ${ }^{a}$ & Male & $22,703 €[19]$ & 0.67 \\
\hline - Penile, distant disease ${ }^{a}$ & Male & $23,182 €[19]$ & 0.48 \\
\hline - Anal cancer, local disease ${ }^{a}$ & Male; Female & $19,534 €[19]$ & 0.76 \\
\hline - Anal cancer, regional disease ${ }^{a}$ & Male; Female & $32,617 €[19]$ & 0.67 \\
\hline - anal cancer, distant disease ${ }^{a}$ & Male; Female & $33,304 €[19]$ & 0.48 \\
\hline - Head \& Neck cancer, local disease ${ }^{a}$ & Male; Female & $22,981 €[19]$ & 0.76 \\
\hline - Head \& Neck cancer, regional disease ${ }^{a}$ & Male; Female & $38,373 €[19]$ & 0.67 \\
\hline - Head \& Neck cancer, distant disease ${ }^{a}$ & Male; Female & $39,181 €[19]$ & 0.48 \\
\hline - Genital warts & Male; Female & $661 €[54]$ & 0.91 \\
\hline - Recurrent respiratory papillomatosis & Male; Female & $26,812 €[56]$ & 0.81 \\
\hline
\end{tabular}

aDisease stages can be related to the traditional Tumour-Node-Metastasis (TNM) classification system as followed: - "Local disease" corresponds to stages I and II TNM classification, i.e., localized primary tumour; "Regional disease" corresponds to stage III TNM classification system, i.e., metastasis to regional lymph nodes; "Distant disease" corresponds to stage IV TNM classification system, i.e., distant metastatic disease 
Zechmeister et al. [19], Brisson et al. (2013) [22], and Jit et al. [56]. The productivity losses as a result of HPV disease were not included in the model.

\section{Cost of screening and diagnostic tests}

A previous Austrian cost-effectiveness analysis of Zechmeister et al. (2007) was used to extract the costs of PAP test, colposcopy and biopsy [20]. Screening by PAP smear was set at $23 €$, colposcopy cost at $9 €$ and Biopsy cost at $28 €$.

All model costs were updated to 2014 Euros using the Consumer price indices in Austria, which was not specific for medical care [57].

\section{Health-related quality of life}

In the absence of Austrian-specific stage-stratified utility data in the population with HPV-related diseases, US data were used. The same utilities were used in the previous evaluations of the quadrivalent vaccine including the one conducted in Austria.

Health utility values for localized and regional cancer were estimated by Myers et al. [58] whereas Gold et al. [59] derived theses values for distant cancer. The other values were assumed by Elbasha et al. [27]. Utility values considered in the model are reported in the Table 2.

\section{Discounting}

In the absence of official health economic recommendation in Austria, discount rates of $3 \%$ for both costs and benefits as reported in the latest economic evaluation performed in the country were used [18]. Alternative discount rates of $1 \%$ and $4 \%$ were tested in the sensitivity analysis.

\section{Time horizon}

An analytic horizon of 100 years was chosen because this was consistent with the time frame from which the system approached a steady state and the majority of the benefits and costs of vaccination could be realized as recently recommended by the European Vaccine Economics Community [60]. This time horizon is in accordance with the ones considered in the other evaluations of the nonavalent vaccine (100 years in Chesson et al. [23]; 70 years in Brisson et al. [22]).

\section{Model calibration and validation}

The model was calibrated on incidence and mortality rates of HPV-related diseases observed in Austria.

The calibration process involved many rounds of iterations to move model outcomes closer to the targets. The following model outcomes were compared against the calibration target in each iteration: cervical cancer incidence, genital warts incidence, vaginal/vulvar/penile/anal/ head and neck cancer incidence, and mortality rates of cervical/vaginal/vulvar/ head and neck cancer.

The variables that affect all or most of the outputs are referred as global variables. These include behavioural parameters, natural history of disease, transmission rates, all-cause mortality and were first adjusted by changing transmission rates. The variables that affect only specific outputs are referred to as specific variables. These include probability of death and rate of seeking treatment for most cancers and were used to fine-tune each disease area.

\section{Epidemiological targets}

Regarding epidemiological data, incidental cases of cancers, Austrian-specific data were retrieved [61]. No Austrian data was available for cervical precancerous lesion incidences. Norwegian incidence data was used, as it was the lowest incidence among 5 different countries in Europe [4]. The incidence and mortality rates for the different cancers, and the incidence rate for genital warts, were adjusted by the proportion of diseases attributable to HPV infection and HPV genotype (Table 3) [4].

The mortality associated with HPV-related cancers was estimated from EUROCARE-5 survival data [62]. EUROCARE (European Cancer Registry) is a collaborative research project on cancer survival in Europe provided by 116 Cancer Registries in 30 European countries over the period 1999-2007. Since data from EUROCARE-5 was available from 15 years old, cancer-associated mortality rates were assumed to be 0 for the population below 15 . As no relative survival by stage was found for Austria, a relative risk for local, regional and distant cancer was calculated according to a Cancer research in the UK [63]. Final mortality rates by stage and by age were obtained by multiplying each mortality rate by the corresponding relative risk.

Table 3 Proportions of cancers and genital warts attributable to HPV infection

\begin{tabular}{llllll}
\hline & Female & & & Male \\
\cline { 2 - 3 } \cline { 5 - 5 } & $\begin{array}{l}\text { 4-valent } \\
\text { vaccination }\end{array}$ & $\begin{array}{l}\text { 9-valent } \\
\text { vaccination }\end{array}$ & & $\begin{array}{l}\text { 4-valent } \\
\text { vaccination }\end{array}$ & $\begin{array}{l}\text { 9-valent } \\
\text { vaccination }\end{array}$ \\
\hline $\begin{array}{l}\text { Cervical } \\
\text { cancer }\end{array}$ & $72.8 \%$ & $89.0 \%$ & - & - \\
Vaginal & $50.7 \%$ & $60.6 \%$ & - & - \\
Vulvar & $14.2 \%$ & $16.2 \%$ & - & - \\
Anal & $76.3 \%$ & $78.7 \%$ & $76.3 \%$ & $78.7 \%$ \\
Penile & - & - & $34.4 \%$ & $34.4 \%$ \\
Head and & $13.6 \%$ & $13.6 \%$ & $16.5 \%$ & $16.5 \%$ \\
Neck & & & & $90 \%$ \\
Genital & $90 \%$ & $90 \%$ & $90 \%$ & \\
warts & & & &
\end{tabular}

Source: Hartwig (2015) [4] 
Overall incidence and mortality by disease are reported in the Table 4.

\section{Model analyses}

The model was used to estimate the total number of disease events related to the HPV type 6/11/16/18/31/33/ 45/52/58-related; the incidence and mortality of cervical cancer, anal cancer and the incidence of CIN and genital warts; the costs of vaccination, screening, diagnosis and management of the disease; the quality-adjusted life years (QALYs) of the model population. Results were reported over 100 years for the different strategies tested. Incremental cost-effectiveness ratios (ICERs) were then calculated by dividing the difference in accumulated costs by the QALY gained.

The interpretation of the incremental cost-effectiveness ratio of nonavalent vaccination in Austria is difficult in the absence of a formal cost-effectiveness threshold. However, international cost-effectiveness thresholds can help to estimate a realistic threshold for Austria:

- in the UK, the JCVI defined the cost-effectiveness threshold for vaccines is between 20,000 and 30,000 $£ /$ QALY (equivalent to 30,000 to $40,000 € /$ QALY in Austria).

- the WHO considers an intervention as very costeffective if the ICER is below 1 GDP per capita $(40,000 €$ for Austria) and cost-effective from 1 to 3 GDP per capita.

Thus it will be assumed that the cost effectiveness threshold in Austria is in the range from $30,000 €$ to $40,000 €$ per QALY gained.

Table 4 Overall incidence of cancers, mortality and genital warts

\begin{tabular}{llllll}
\hline & \multicolumn{2}{l}{$\begin{array}{l}\text { Overall incidence } \\
\text { (per 100.000) }\end{array}$} & & \multicolumn{2}{l}{$\begin{array}{l}\text { Overall mortality } \\
\text { (per 100.000) }\end{array}$} \\
\cline { 2 - 3 } \cline { 5 - 6 } & Female & Male & & Female & Male \\
\hline Cervical & 8.4 & - & & 4.1 & - \\
CIN 1 & 303.0 & - & & - & - \\
CIN 2+ & 138.8 & - & & - & - \\
Vaginal & 1.1 & - & & 0.2 & - \\
Vulvar & 3.1 & - & & 0.9 & - \\
Anal & 1.8 & 1.0 & & 0.3 & 0.3 \\
Oral cavity & 3.9 & 7.7 & & 0.8 & 2.5 \\
Larynx & 0.9 & 9.1 & & 0.3 & 1.6 \\
Head \& Neck & 7.1 & 25.6 & & 1.9 & 7.5 \\
Genital warts & 141.2 & 146.5 & & - & - \\
Penile & - & 1.2 & & - \\
\hline Source: Hartwig (2015) [4], ICO - Austria (2015) [61], Cancer research UK [63], \\
Robert Koch Institute (2014) [74] and internal data for H\&N and genital warts
\end{tabular}

Sensitivity analyses were performed deterministically, modifying the value of one base case parameter at a time. The following key parameters were tested: duration of protection (20 years), utilities (from Sullivan et al.), discount rates ( $1 \%$ or $4 \%$ for both health and outcomes), cost of diseases $(+/-50 \%)$, variation in the VCR of boys and girls $(+/-20 \%)$, increased vaccination coverage rate in boys $(+10 \%)$ and decreased compliance rate $(90 \%$ - assuming no efficacy if only one dose is administered). No probabilistic sensitivity analysis has been performed.

\section{Results}

\section{Calibration}

The calibration on overall incidence and mortality was good on a majority of the calibrated diseases (cervical, anal, penile, head and neck cancers and genital warts) as reported in Table 5.

However, a calibration on cervical precancerous was achieved but calibration results could not fit with the

Table 5 Comparison of overall incidence $(/ 100,000)$ between target and calibration

\begin{tabular}{|c|c|c|c|c|}
\hline & \multicolumn{2}{|c|}{ 4-valent vaccination } & \multicolumn{2}{|c|}{ 9-valent vaccination } \\
\hline & Target & $\begin{array}{l}\text { Calibration } \\
\text { results }\end{array}$ & Target & $\begin{array}{l}\text { Calibration } \\
\text { results }\end{array}$ \\
\hline \multicolumn{5}{|l|}{ Female } \\
\hline \multicolumn{5}{|l|}{ Incidence } \\
\hline $\begin{array}{l}\text { Cervical } \\
\text { cancer }\end{array}$ & 6.12 & 6.12 & 7.48 & 7.48 \\
\hline CIN $2+$ & 63.15 & 22.29 & 114.23 & 27.62 \\
\hline Vaginal & 0.56 & 0.05 & 0.67 & 0.05 \\
\hline Vulvar & 0.44 & 0.08 & 0.50 & 0.08 \\
\hline Anal & 1.37 & 1.37 & 1.42 & 1.42 \\
\hline Genital warts & 127.08 & 126.93 & 127.08 & 126.93 \\
\hline Head and Neck & 0.96 & 0.96 & 0.96 & 0.96 \\
\hline \multicolumn{5}{|l|}{ Mortality } \\
\hline $\begin{array}{l}\text { Cervical } \\
\text { cancer }\end{array}$ & 2.98 & 2.98 & 3.65 & 3.65 \\
\hline Vaginal & 0.20 & 0.02 & 0.10 & 0.02 \\
\hline Vulvar & 0.90 & 0.03 & 0.15 & 0.03 \\
\hline Anal & 0.23 & 0.23 & 0.24 & 0.24 \\
\hline \multicolumn{5}{|l|}{ Male } \\
\hline \multicolumn{5}{|l|}{ Incidence } \\
\hline Penile cancer & 0.41 & 0.41 & 0.41 & 0.41 \\
\hline Anal cancer & 0.76 & 0.76 & 0.79 & 0.79 \\
\hline Genital warts & 131.85 & 131.52 & 131.85 & 131.52 \\
\hline Head and Neck & 4.23 & 4.25 & 4.23 & 4.25 \\
\hline \multicolumn{5}{|l|}{ Mortality } \\
\hline Penile cancer & 0.10 & 0.10 & 0.10 & 0.10 \\
\hline Anal cancer & 0.23 & 0.22 & 0.24 & 0.23 \\
\hline
\end{tabular}



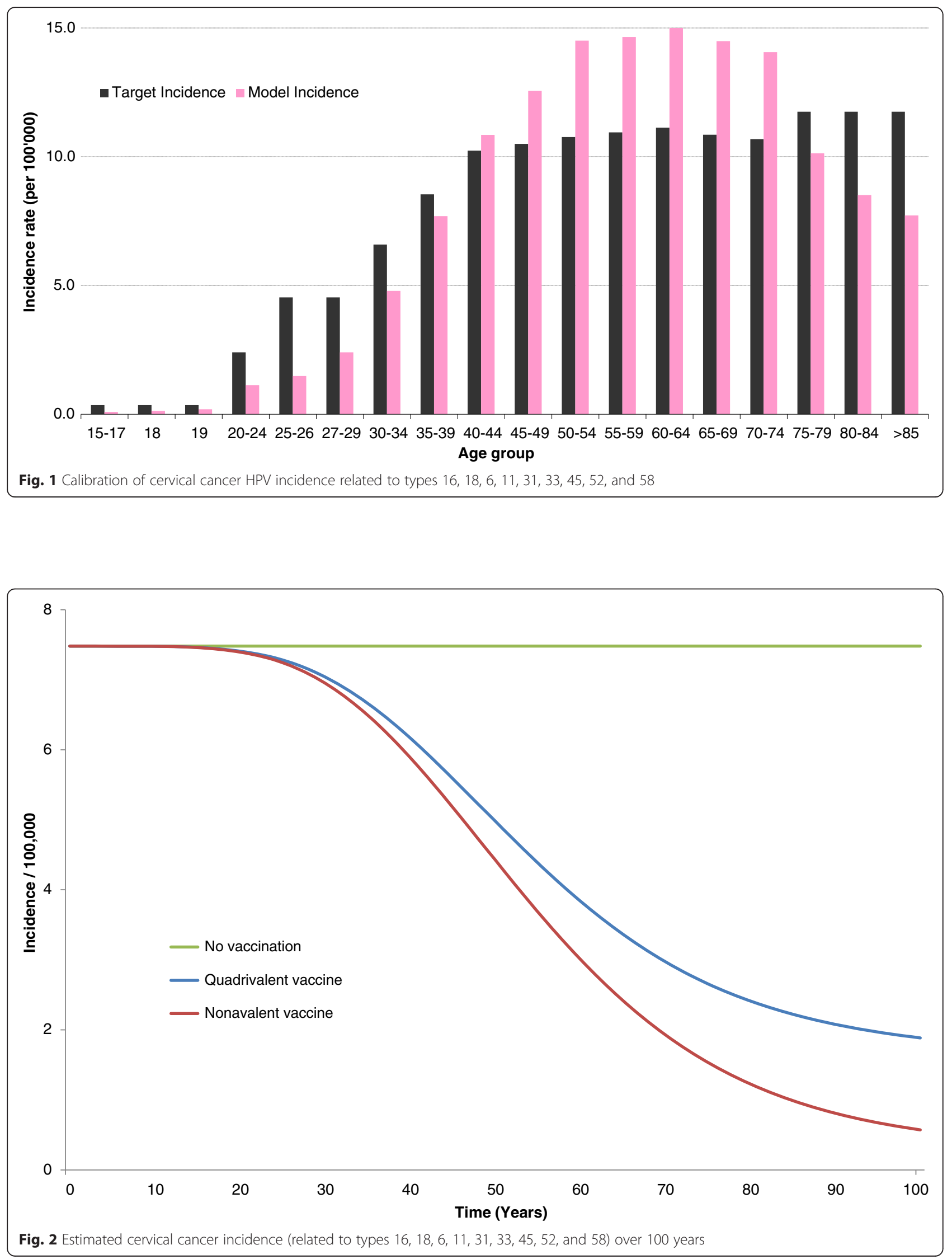
targets, producing really low values. For the diseases non-calibrated (vaginal and vulvar cancer), the model also reports lower values than expected. As a consequence, the model underestimates the benefits of the HPV vaccines on the cervical precancerous lesions and vaginal and vulvar cancers.

As the non-age specific calibration, the age-specific calibration shows good fit to the epidemiological data for the calibrated diseases (anal cancer, cervical cancer, genital warts) and head \& neck cancers but underestimate the incidence of CINs, and vulvar and vaginal cancers (Fig. 1).

\section{Health outcomes}

The public health impact of universal vaccination on cervical cancer incidence is shown in Fig. 2. At 100 years, the nonavalent vaccine is estimated to reduce cervical cancer incidence by $92 \%$, corresponding to an additional $17 \%$ decrease compared to the strategy of vaccination by Gardasil ${ }^{\circ}$.

The $92 \%$ decrease in cervical cancer incidence corresponds to 13,603 cervical cancers and 5937 deaths averted compared to no vaccination over 100 years. The incremental benefit of nonavalent vaccine over the quadrivalent one is estimated to 2544 cervical cancer cases and 1124 cervical deaths over 100 years.
Incidences of precancerous lesions of the cervix (Cervical Intraepithelial Neoplasia 2/3) are estimated to be reduced by $96 \%$ with the nonavalent vaccine, corresponding to an additional $20 \%$ decrease compared to the strategy of vaccination by the quadrivalent vaccine. The nonavalent vaccine could avert an additional 14,893 cervical precancerous lesions over 100 years, compared to the quadrivalent, over 100 years (Fig. 3).

Nonavalent vaccination has an earlier effect on precancerous cervical lesion incidence reduction than for cancers. Indeed, an important burden reduction of precancerous lesion incidences is noticeable after 20 years. The incidence reductions by disease types are summarized in Table 6.

\section{Cost-effectiveness}

Vaccinating one cohort of Austrian girls and boys aged 9 with the nonavalent vaccine, was cost-saving at a vaccine price up to $113 €(+3 €$ vs the quadrivalent vaccine) and still cost-effective up to a price of $153 €(+43 €)$, assuming a cost-effectiveness threshold of 30,000 €/QALY gained, compared to the quadrivalent vaccine at a price of $110 €$ (Fig. 4). To note, should the quadrivalent vaccine price change, the vaccine price increments allowing the

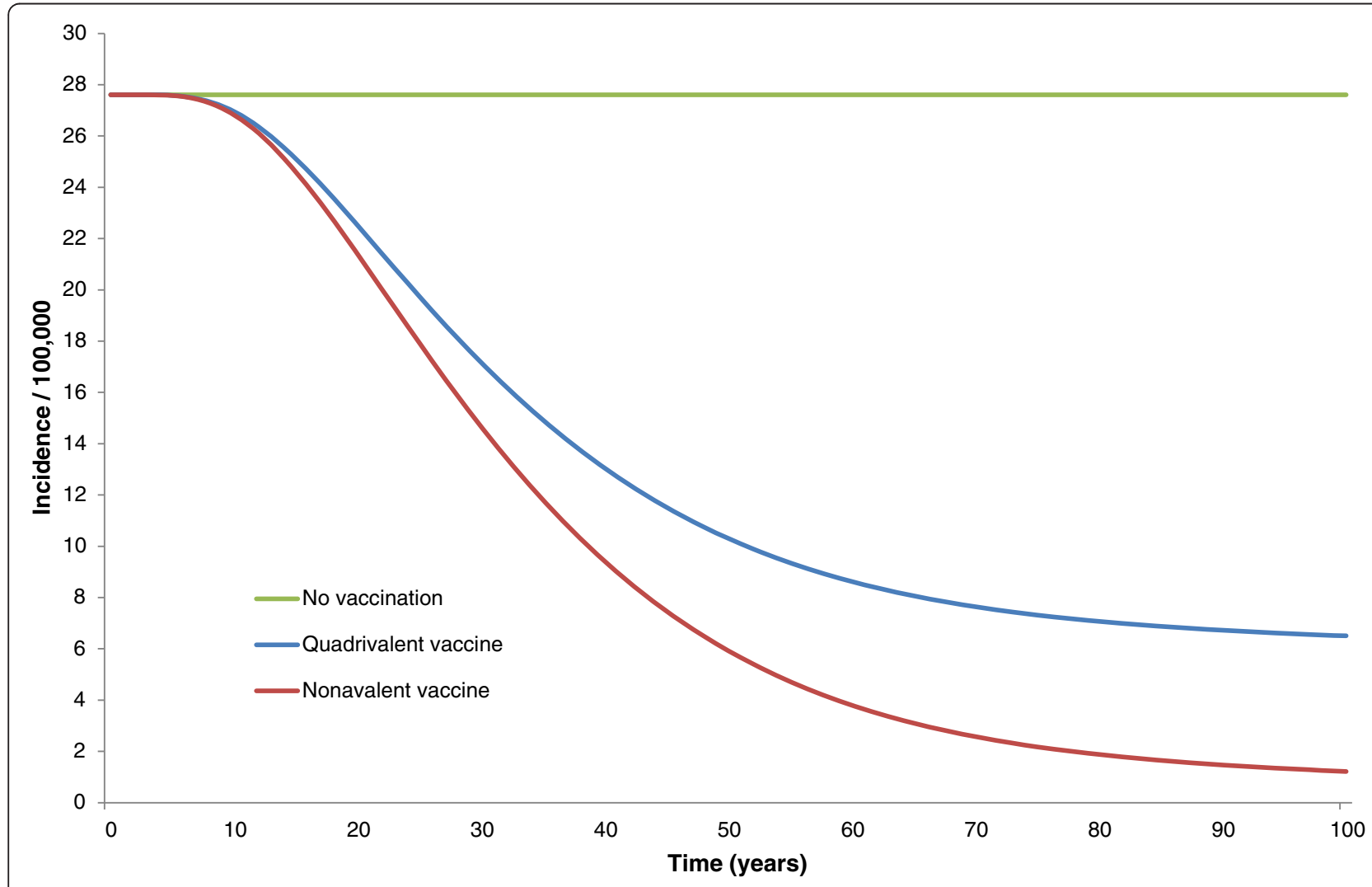

Fig. 3 Estimated CIN2/3 incidences (related to types 16, 18, 6, 11, 31, 33, 45, 52, and 58) over 100 years 
Table 6 Incidence reduction with quadrivalent and nonavalent vaccination at steady-state

\begin{tabular}{lll}
\hline & 4 -valent vaccination & 9 -valent vaccination \\
\hline Female & & \\
Cervical incidence & $-75 \%$ & $-92 \%$ \\
Cervical death & $-74 \%$ & $-91 \%$ \\
Genital warts & $-85 \%$ & $-85 \%$ \\
CIN 1 & $-74 \%$ & $-96 \%$ \\
CIN 2+ & $-76 \%$ & $-96 \%$ \\
Vaginal incidence & $-91 \%$ & $-91 \%$ \\
Vulvar incidence & $-92 \%$ & $-92 \%$ \\
Anal incidence & $-80 \%$ & $-83 \%$ \\
Anal death & $-78 \%$ & $-81 \%$ \\
H \& N incidence & $-81 \%$ & $-81 \%$ \\
Male & & \\
Anal incidence & $-76 \%$ & $-78 \%$ \\
Anal death & $-74 \%$ & $-76 \%$ \\
Genital warts & $-79 \%$ & $-79 \%$ \\
Penile incidence & $-54 \%$ & $-55 \%$ \\
H \& N incidence & $-77 \%$ & $-77 \%$ \\
\hline
\end{tabular}

nonavalent vaccine to be cost-effective $(+43 €)$ or costsaving ( $+3 €$ ) would remain unchanged.

\section{Sensitivity analyses}

One-way sensitivity analyses were performed to test for uncertainty are presented in Fig. 5. The base case ICER of $16,441 €$ /QALY gained was produced at an assumed nonavalent vaccine price of $135 €$ (based on US price). The costs and QALYs of the strategies tested in the base case are reported in the Table 7 . The factors that considerably influenced the cost-effectiveness result, in addition to the vaccine price, were the discount rate and the duration of protection.

The nonavalent vaccine price has a significant impact on the ICER: universal vaccination with nonavalent vaccine was found to be cost-saving at a price of $113 €$ and cost-effective i.e., with an ICER $<30,000 € /$ QALY gained up to a price of $153 €$ compared to the quadrivalent vaccination.

Whichever the parameter that was varied, universal vaccination with the nonavalent vaccine remained below 30,000 €/QALY gained compared with universal vaccination with Gardasil $^{\oplus}$, ranging from $16,441 €$ to $28,065 € /$ QALY gained. Varying utilities $[64,65]$, cost of

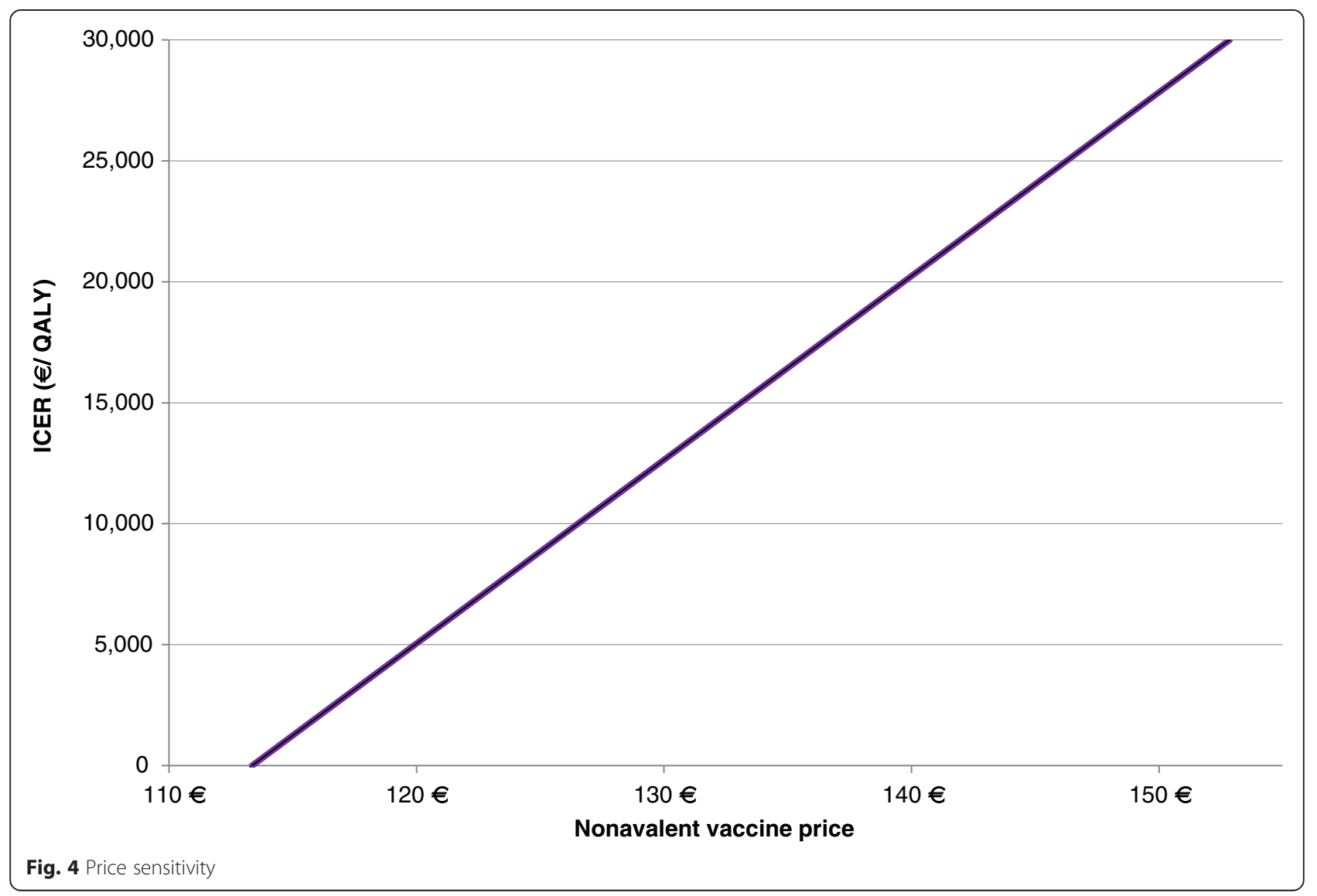




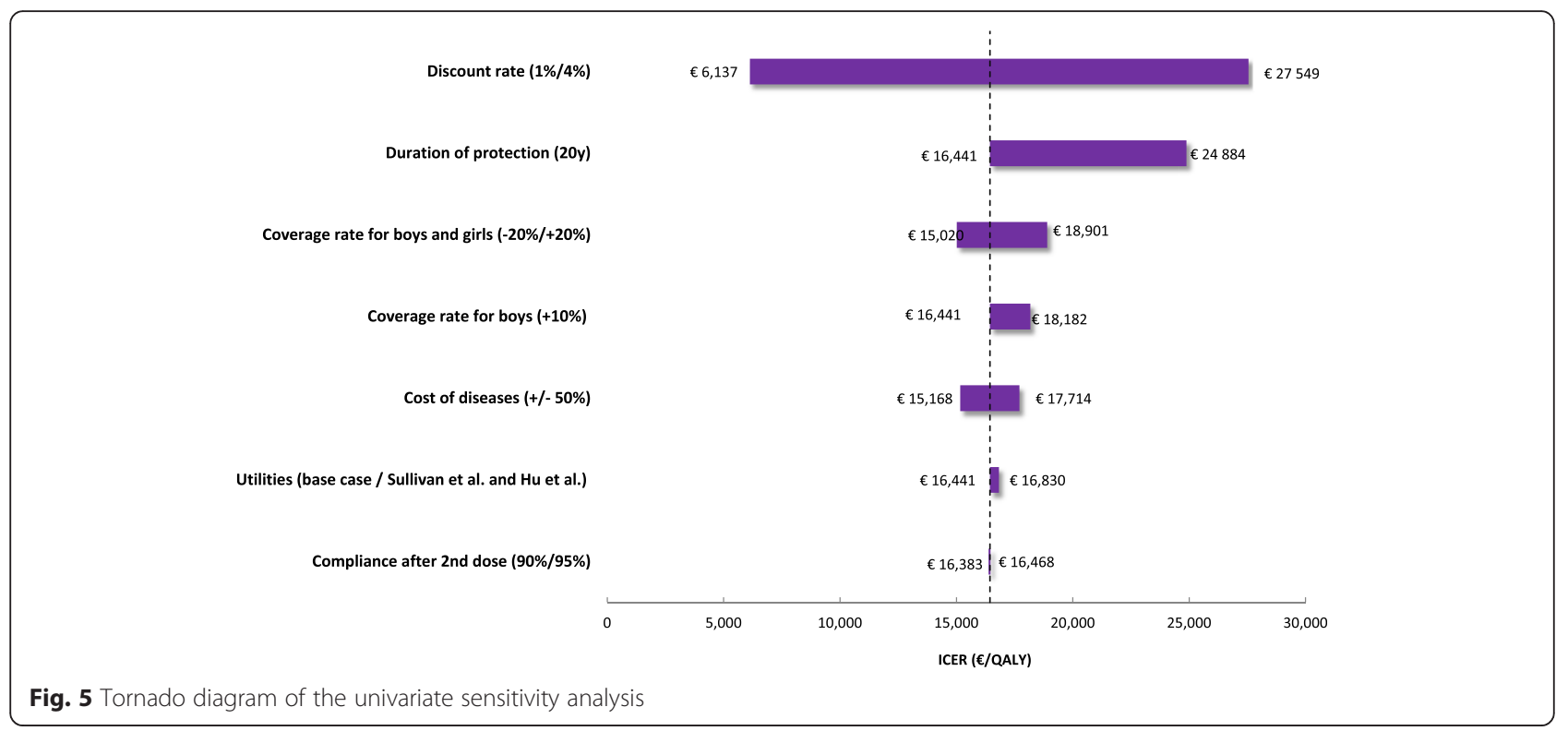

diseases and coverage have shown a moderate influence. An increased vaccination coverage in boys tended to increase the ICER.

\section{Discussion}

The present study assessed the cost-effectiveness of nonavalent vaccination in the Austrian setting by adapting a dynamic model originally designed for the US. The adaptation was achieved through collection and selection of the most appropriate data from a number of countries to reflect the current Austrian epidemiological, medical and economical context, as closely as possible.

The analyses showed that nonavalent vaccination would have a great impact on the burden of HPV-related diseases in Austria. Assuming a vaccination coverage of $60 \%$ and $40 \%$ respectively in girls and boys aged 9 , the nonavalent vaccination would reduce cervical cancer incidence related to the 9 HPV types by $92 \%$, CIN $2+$ by $96 \%$, genital warts by $85 \%$ for girls and $79 \%$ for boys, and anal cancer incidence by $83 \%$ and $78 \%$ for girls and boys over 100 years, respectively compared to a no vaccination strategy. Overall universal vaccination with nonavalent vaccine would avert 23,652 cancer cases and 8399 cancer deaths,

Table 7 Costs and QALY of the quadrivalent and nonavalent vaccination strategies

\begin{tabular}{llll}
\hline & $\begin{array}{l}\text { 4-valent } \\
\text { vaccination }\end{array}$ & $\begin{array}{l}\text { 9-valent } \\
\text { vaccination }\end{array}$ & Difference \\
\hline${\text { Costs/person }(€)^{\text {a }}}$ & 288.44 & 297.18 & 8.74 \\
QALYs/person $^{\text {b }}$ & 26.81176 & 26.81229 & 0.00053 \\
$\begin{array}{l}\text { Cost/QALY } \\
(€ / Q A L Y)\end{array}$ & - & - & 16.441 \\
\hline
\end{tabular}

${ }^{\mathrm{a}}$ Costs rounded to 0.01

${ }^{\mathrm{b}} \mathrm{QALY}$ rounded to 0.00001 over 100 years compared to no vaccination. Compared to Gardasil ${ }^{\circ}$, the analyses showed nonavalent vaccine has a substantial impact on cervical cancer and precancerous lesions incidences with an incremental decrease of $18 \%$ and $22 \%$, respectively, corresponding to 2544 cervical cancers and 23,174 precancerous lesions cases averted over 100 years. The benefits on anal cancer appeared to be less pronounced. This is easily explained since only $2.4 \%$ of anal cancers are attributed to HPV types $31,33,45,52,58$ whereas types 16 and 18 already included in Gardasil ${ }^{\circ}$ are responsible for $76,3 \%$ of the anal cancers. The current analysis demonstrates that even if the coverage rates are relatively low, especially for boys, nonavalent vaccination program has an important impact on public health. Interestingly, concrete benefits of the nonavalent vaccination come early thanks to the strong effect on genital warts and precancerous lesions. Indeed, the model estimates that as early as 20 years after the beginning of the vaccination program, incidence of genital warts and CIN2+ in females is decreased respectively by $58 \%$ and $23 \%$, which is also significant from an economic perspective as at year 20, the costs averted for genital warts and CIN2+ represent $22 \mathrm{M} €$ and $77 \%$ of the total costs averted at this time. Moreover, these estimates are likely to be very conservative, since literature reported real world-impact of the quadrivalent vaccination comes even faster with a dramatic decline in genital warts incidence observed in the first 2 years following the vaccination program implementation $[66,67]$ that led to a nearly disappearance of genital warts in the targeted cohorts as soon as 4 years after the commencement of the vaccination program in Australia [68]. In the same country, a decline in CIN2+ by $54 \%$ as soon as 7 years after the implementation of the vaccination program was also reported [69]. 
The present analysis showed that universal vaccination with 9-valent vaccine is cost-saving up to a price of 113 $€$ and cost effective up to a price of $153 €$, in comparison to universal vaccination with quadrivalent vaccine at a price of $110 €$, assuming cost-effectiveness threshold of $30,000 € /$ QALY gained. With a theoretical nonavalent vaccine price assumed of $135 €$, vaccinating girls and boys aged 9 would be very cost-effective, compared to the current strategy, with an ICER of $16,441 € / Q A L Y$ gained.

Univariate sensitivity analyses were conducted to assess uncertainty related to discount rate, vaccine's duration of protection, vaccination coverage rates, disease costs, and QALYs. Discount rates and duration of protection were the most influential factors. However, whichever the parameter that was varied, universal vaccination of one cohort of girls and boys aged 9 remained very cost-effective compared with the vaccination strategy with the quadrivalent vaccine. These economic results can hardly be put in perspective since it is the first economic evaluation of the nonavalent HPV vaccine in Austria. However, compared to the existing economic evaluation conducted in North America, our results seems more conservative since results of the three US models concluded that - assuming comparable vaccination coverage rates than in the present study (62\% and $38 \%$ coverage by 17 years of age) - universal nonavalent vaccination was cost-saving compared to quadrivalent universal vaccination in the US considering an incremental price per dose of $10 \%$ (+13 US\$) [23].

The current analysis has several limitations that must be presented. First, the model involved numerous parameters and not all the needed parameters could be found from Austria-specific studies. However, nonAustrian specific values have been validated by experts. Second, the cervical intraepithelial neoplasia incidences are substantially under-estimated by the model. Indeed, while the incidence of CIN2+ related to the serotypes $16,18,31,33,45,52,58$ was estimated to be 114 / 100,000, the model estimates 27.62 / 100,000 corresponding to a 5-fold underestimation. Furthermore, the additional benefits of nonavalent vaccination on CIN may also be underestimated. In the study from Hartwig et al. [4], results showed that the HPV6/11/16/18 are responsible for about $45 \%$ of CIN2+, whereas HPV6/11/16/18/31/ $33 / 45 / 52 / 58$ targeted by the nonavalent vaccine account for $82 \%$ of $\mathrm{CIN} 2+$ meaning the nonavalent $\mathrm{HPV}$ infections were responsible for 1.8 times more CIN2+ compared the quadrivalent HPV whereas the results obtained from the calibrated model indicated that nonavalent HPV accounts for 1.24 times more for CIN2+ than quadrivalent HPV, minimizing greatly the benefit of the nonavalent vaccine on CIN compared to the quadrivalent. Overall, although nonavalent vaccination was estimated to bring important benefits on CINs, the latter are dramatically underestimated by our model. The inability to calibrate appropriately on the CIN is explained by the natural history parameters of the model that do not allow us to have a good fit on both cervical and CIN incidence. The choice was made to privilege the cervical cancer calibration since it is the most impactful parameter. This underestimation constitutes a limit of the model that must be fixed in the future. Nevertheless, the benefits of nonavalent vaccination being underestimated, our analyses remain conservative. Likewise, vaginal and vulvar incidences are under-estimated. These model limitations should be corrected in the future but led to increased -and consequently conservative ICER estimate for the nonavalent vaccination strategy. Third, the model assumes disease attribution for the HPV types $31,33,45,52,58$ only for cervical and anal diseases. Benefit of the nonavalent vaccine on vulvar and vaginal cancers are consequently underestimated in our analyses. However, the vulvar and vaginal cancer incidence being far lower than cervical cancer incidence, this limitation should marginally impact the analysis results. Fourth, the economic benefits of HPV vaccination are underestimated since the indirect effects of cancer (loss of income for patients due to disruption in professional life, indirect costs for childcare or caregiver costs, increase of private insurance cost...) are not considered in this analysis. Fifth, the model focused on heterosexual transmission of HPV and did not incorporate transmission between men who have sex with men (MSM), or between homosexuals and heterosexuals. Last, the model does not consider the population movement (immigration and emigration).

It must be emphasized that by expanding the spectrum of prevention to $80-90 \%$ of HPV-related cancers and other diseases, the nonavalent vaccine - should the coverage rates be high enough - contribute to reframe the cervical cancer prevention model shifting towards a more comprehensive HPV prevention model. Indeed, as nonavalent vaccination will further lower the prevalence rates of cervical lesions, the performance (positive predictive value, PPV) of Pap cytology test will decrease. Pap cytology test performance falls dramatically at lesion rates $<20 \%$. With further reduction in lesions prevalence consequent to HPV vaccination $(<5 \%)$, the clinical utility of the PPV becomes substantially affected with the implication being that the vast majority of cases identified on screening will result in unnecessary clinical management and follow-up and attendant higher costs [70, 71]. This paradigm shift is already observed in the Netherlands where the HPV DNA test should be implemented as first line screen for cervical cancer prevention in 2016. Furthermore, it has to be highlighted the societal impact of nonavalent vaccination goes far beyond the epidemiological outcomes reported above. Indeed, the epidemiological change induced by the nonavalent vaccine translates notably in less emotional 
suffering linked to screening outcomes (fear about the future and potential fertility concerns, possible lifelong disability post-surgery, etc....) and it preserves fertility by avoiding potential adverse pregnancy outcomes post cervical therapy (pre-term birth increased by 2 to 3 after conisation) [72]. These effects on patient's lives are not taken into account in the evaluation but are far to be negligible [73].

\section{Conclusion}

The results of the present evaluation show that vaccinating $60 \%$ of girls and $40 \%$ of boys aged 9 in Austria with a nonavalent vaccine will substantially reduce the incidence of cervical cancer, CIN and anal cancer by $20 \%, 17 \%$ and $3 \%$ respectively compared to the existing strategy. The vaccination strategies performed with the nonavalent vaccine in the current study were all found to be costeffective compared to the current quadrivalent vaccination strategy by considering a cost-effectiveness threshold of 30,000€/QALY gained.

The nonavalent vaccine has been considered an important advance over Gardasil ${ }^{\circ}$, as the nine vaccine types account for about $90 \%$ of cervical cancer. The present study demonstrate that the switch from Gardasil ${ }^{\circ}$ to the nonavalent universal vaccination in Austria can bring substantial incremental public health benefits and would constitute a cost-effective intervention.

\section{Ethics approval and consent to participate}

Not applicable. The study does not involve human subjects.

\section{Consent for publication}

Not applicable. The article does not include any material relating to individual participant.

\section{Availability of data and materials}

All data supporting our findings will be shared upon request.

\section{Endnotes}

$1_{*}$ Considering 1 USD $=0.906849$ EUR (www.xe.com, visited the $28^{\text {th }}$ of July 2015)

\begin{abstract}
Abbreviations
CEA: cost-effectiveness analysis; CHMP: Committee for Medicinal Products for Human Use; CIN: cervical intraepithelial neoplasia; CIS: carcinoma in situ; HPV: Human Papillomavirus; ICER: incremental cost-effectiveness ratio; MSM: men who have sex with men; NATSAL: National Survey of Sexual Attitudes and Lifestyles; Pap: papanicolaou smear; QALY: quality-adjusted life year; QoL: quality of life; RRP: recurrent respiratory papillomatosis; ValN: vaginal intraepithelial neoplasia; VIN: vulvar intraepithelial neoplasia.
\end{abstract}

\section{Competing interests}

Louis Boiron, Nathalie Largeron, Bernard Prager and Mathieu Uhart are employees of Sanofi Pasteur MSD. Elmar Joura is associate Professor of Gynecology and Obstetrics at the Medical University of Vienna, General Hospital (AKH), and Comprehensive Cancer Center Vienna.

\section{Authors' contributions}

Louis Boiron collected the data, produced the analyses and wrote the manuscript. Elmer Joura interpreted the data and revised the manuscript. Nathalie Largeron was involved in the data collection, study design and revised the manuscript. Bernard Prager was involved in the data collection, contributed to the study design and revised the manuscript. Mathieu Uhart contributed to the study design, interpreted the data and wrote the manuscript. All authors read and approve the final version of the manuscript.

\section{Acknowledgements}

The authors warmly thank Jeff Kyle and Matthew Pillsbury, employees of Merck Sharp and Dohme, for their great support in the model calibration; Marjorie Adam, employee of Sanofi Pasteur MSD, for her valuable advice during the manuscript review. Thalia Nikoglou, former employee of Sanofi Pasteur MSD for her substantial contribution to this work.

\section{Author details}

${ }^{1}$ Sanofi Pasteur MSD, 162 avenue Jean Jaurès CS 50712 69367, Lyon Cedex 07, France. ${ }^{2}$ Department of Gynecology and Obstetrics, Medical University of Vienna, Comprehensive Cancer Center, Vienna, Austria. ${ }^{3}$ Sanofi Pasteur MSD, Campus 21Europarin F11/402, Brunn am Gebirge A-2345, Austria.

Received: 27 November 2015 Accepted: 25 March 2016

Published online: 16 April 2016

\section{References}

1. Stanley M. HPV vaccination in boys and men. Hum Vaccin Immunother. 2014;10:2109-11.

2. Centers for Disease Control and Prevention. Genital HPV Infection - Fact Sheet. cdc.gov. 23-1-2015.

3. U.S. Food and Drug Administration. HPV (human papillomavirus). fda.gov. 13-3-2015. 6-8-2015.

4. Hartwig S, Baldauf JJ, Dominiak-Felden G, Simondon F, Alemany L, de Sanjosé S, et al. Estimation of the epidemiological burden of HPV-related anogenital cancers, precancerous lesions, and genital warts in women and men in Europe: Potential additional benefit of a nine-valent second generation HPV vaccine compared to first generation HPV vaccines. Papillomavirus Res. 2015;1:90-100.

5. World Health Organization. Human papillomavirus (HPV) and cervical cancer. who.int. 2015. 3-1-2015.

6. European Centre for Disease Prevention and Control. Introduction of HPV vaccines in EU countries - an update. Stockholm: ECDC. 2012.

7. Merck. Merck's investigational 9-valent HPV vaccine, V503, prevented 97 percent of cervical, vaginal and vulvar precancers caused by five additional HPV types, in phase III study. 4-11-2013. 25-9-2015.

8. European Medicines Agency. Summary of opinion: Gardasil 9 human papillomavirus 9-valent vaccine (recombinant, adsorbed). 26-3-2015. 25-9-2015.

9. U.S.Food and Drug Administration. FDA approves Gardasil 9 for prevention of certain cancers caused by five additional types of HPV. http://www.fda. gov/NewsEvents/Newsroom/PressAnnouncements/ucm426485.htm. Accessed 14 Apr 2016

10. Joura EA, Ault KA, Bosch FX, Brown D, Cuzick J, Ferris D, et al. Attribution of 12 high-risk human papillomavirus genotypes to Infection and cervical disease. Cancer Epidemiol Biomarkers Prev. 2014;23:1997-2008.

11. Brisson M, van de Velde N, Franco EL, Drolet M, Boily MC. Incremental impact of adding boys to current human papillomavirus vaccination programs: role of herd immunity. J Infect Dis. 2011;204:372-6.

12. Canfell K, Chesson H, Kulasingam SL, Berkhof J, Diaz M, Kim JJ. Modeling preventative strategies against human papillomavirus-related disease in developed countries. Vaccine. 2012;30 Suppl 5:F157-67.

13. Low GM, Attiga YS, Garg G, Schlegal R, Gallicano Gl. Can male vaccination reduce the burden of human papillomavirus-related disease in the United States? Viral Immunol. 2012;25:174-86.

14. Stupiansky NW, Alexander AB, Zimet GD. Human papillomavirus vaccine and men: what are the obstacles and challenges? Curr Opin Infect Dis. 2012;25:86-91.

15. Audisio RA, Icardi G, Isidori AM, Liverani CA, Lombardi A, Mariani L, et al. Public health value of universal HPV vaccination. Crit Rev Oncol/Hematol. 2016;97:157-67. 
16. Ali H, Donovan B, Wand H, Read TR, Regan DG, Grulich AE, et al. Genital warts in young Australians five years into national human papillomavirus vaccination programme: national surveillance data. BMJ. 2013;346:f2032.

17. Mariani L, Vici P, Suligoi B, Checcucci-Lisi G, Drury R. Early direct and indirect impact of quadrivalent HPV (4HPV) vaccine on genital warts: a systematic review. Adv Ther. 2015:32:10-30.

18. Bresse X, Goergen C, Prager B, Joura E. Universal vaccination with the quadrivalent HPV vaccine in Austria: impact on virus circulation, public health and cost-effectiveness analysis. Expert Rev Pharmacoecon Outcomes Res. 2014;14:269-81.

19. Zechmeister I, Freiesleben de Blasio B, Radlberger P, Wild C, Kvas E, Garnett $G$, et al. Ökonomische Evaluation der Impfung gegen humane Papillomaviren (HPV-Impfung) in Österreich. 2007.

20. Kundi M. Health economics of HPV vaccination in Austria - Costeffectiveness of vaccinating 12 year old girls. Value Health J. 2009.

21. Zechmeister I, Blasio BF, Garnett G, Neilson AR, Siebert U. Cost-effectiveness analysis of human papillomavirus-vaccination programs to prevent cervical cancer in Austria. Vaccine. 2009;27:5133-41.

22. Brisson M. Incremental cost-effectiveness of the 9-valent vs. the 4-valent HPV vaccine in the U.S. 2014

23. Chesson H. Overview of cost-effectiveness of 9-valent HPV vaccination. 2015.

24. Weiss T, Asbach EJ. Potential health and economic impact of the investigational 9-valent HPV vaccine in the United States. 2014

25. Brisson M, Laprise JF, Chesson H, Drolet M, Malagon T, Boily MC, et al. Health and economic impact of switching from a 4-valent to a 9-valent HPV vaccination program in the United States. J Natl Cancer Inst. 2016;108:djv282.

26. Elbasha EH, Dasbach EJ, Insinga RP, Elbasha EH, Dasbach EJ, Insinga RP. Supplementary online appendix. 2006.

27. Elbasha EH, Dasbach EJ, Insinga RP. Model for assessing human papillomavirus vaccination strategies. Emerg Infect Dis. 2007;13:28.

28. Elbasha EH, Dasbach EJ. An integrated economic evaluation and HPV disease transmission models - Technical report accompanying the manuscrit "Impact on vaccinating boys and men against HPV in the United States". 2010.

29. Elbasha EH, Dasbach EJ. Impact of vaccinating boys and men against HPV in the United States. Vaccine. 2010;28:6858-67.

30. Statistics Austria. Population by sex and age groups since 1869. 2015.

31. Mercer CH, Tanton C, Prah P, Erens B, Sonnenberg P, Clifton S, et al. Changes in sexual attitudes and lifestyles in Britain through the life course and over time: findings from the National Surveys of Sexual Attitudes and Lifestyles (Natsal). Lancet. 2013;382:1781-94.

32. Statistisches Bundesamt. Fallpauschalenbezogene Krankenhausstatistik. 2008

33. Statistics Austria. Anzahl der unterschiedlichen medizinischen Einzelleistungen bei Spitalsentlassungen 2013. 2015. 25-11-2014

34. Leitge BA. Zervixkarzinomvorsorge in Österreich: Vorbild oder Auslaufmodell? Doktorin der gesamten Heilkunde. AustriaMedizinischen Univesität Graz; 2011.

35. Wagner R. Bundersministerium für gesundheit: Österreichischer impftag. 2015.

36. Ault KA. Effect of prophylactic human papillomavirus L1 virus-like-particle vaccine on risk of cervical intraepithelial neoplasia grade 2, grade 3, and adenocarcinoma in situ: a combined analysis of four randomised clinical trials. Lancet. 2007:369:1861-8.

37. Garland SM, Hernandez-Avila M, Wheeler CM, Perez G, Harper DM, Leodolter $S$, et al. Quadrivalent vaccine against human papillomavirus to prevent anogenital diseases. N Engl J Med. 2007;356:1928-43.

38. Giuliano AR, Palefsky JM, Goldstone S, Moreira Jr ED, Penny ME, Aranda C, et al. Efficacy of quadrivalent HPV vaccine against HPV Infection and disease in males. N Engl J Med. 2011;364:401-11.

39. Joura EA, Giuliano AR, Iversen OE, Bouchard C, Mao C, Mehlsen J, et al. A 9-valent HPV vaccine against infection and intraepithelial neoplasia in women. N Engl J Med. 2015;372:711-23.

40. Joura EA, Leodolter S, Hernandez-Avila M, Wheeler CM, Perez G, Koutsky LA, et al. Efficacy of a quadrivalent prophylactic human papillomavirus (types 6, 11, 16, and 18) L1 virus-like-particle vaccine against high-grade vulval and vaginal lesions: a combined analysis of three randomised clinical trials. Lancet. 2007;369:1693-702

41. Palefsky JM, Giuliano AR, Goldstone S, Moreira Jr ED, Aranda C, Jessen H, et al. HPV vaccine against anal HPV infection and anal intraepithelial neoplasia. N Engl J Med. 2011;365:1576-85.

42. SPMSD. Gardasil summary of product characterisitics. 2014.

43. Nygard M, Saah A, Munk C, Tryggvadottir L, Enerly E, Hortlund M, et al. Evaluation of the long-term anti-human papillomavirus 6 (HPV6), 11, 16, and
18 immune responses generated by the quadrivalent HPV vaccine. Clin Vaccine Immunol. 2015;22:943-8.

44. Kjaer SK, Nygard M, Dillner J. Long-term effectiveness and safety of Gardasil in the Nordic countries. Sevilla: Eurogin; 2015.

45. Fraser C, Tomassini JE, Xi L, Golm G, Watson M, Giuliano AR, et al. Modeling the long-term antibody response of a human papillomavirus (HPV) virus-like particle (VLP) type 16 prophylactic vaccine. Vaccine. 2007;25:4324-33.

46. Schobert D, Remy V, Schoeffski O. Cost-effectiveness of vaccination with a quadrivalent HPV vaccine in Germany using a dynamic transmission model. Health Econ Rev. 2012;2:19.

47. Malagon T, Drolet M, Boily MC, Franco EL, Jit M, Brisson J, et al. Crossprotective efficacy of two human papillomavirus vaccines: a systematic review and meta-analysis. Lancet Infect Dis. 2012;12:781-9.

48. Mesher D, Soldan K, Howell-Jones R, Panwar K, Manyenga P, Jit M, et al. Reduction in HPV 16/18 prevalence in sexually active young women following the introduction of HPV immunisation in England. Vaccine. 2013;32:26-32.

49. Markowitz LE, Hariri S, Lin C, Dunne EF, Steinau M, McQuillan G, et al. Reduction in human papillomavirus (HPV) prevalence among young women following HPV vaccine introduction in the United States, National Health and Nutrition Examination Surveys, 2003-2010. J Infect Dis. 2013;208:385-93.

50. Tabrizi SN, Brotherton JM, Kaldor JM, Skinner SR, Liu B, Bateson D, et al. Assessment of herd immunity and cross-protection after a human papillomavirus vaccination programme in Australia: a repeat cross-sectional study. Lancet Infect Dis. 2014;14:958-66.

51. Kavanagh K, Pollock KG, Potts A, Love J, Cuschieri K, Cubie H, et al. Introduction and sustained high coverage of the HPV bivalent vaccine leads to a reduction in prevalence of HPV 16/18 and closely related HPV types. Br J Cancer. 2014;1 10:2804-11.

52. World Health Organization. Comprehensive Cervical Cancer Control: A Guide to Essential Practice. 2014.

53. Centers for Disease Control and Prevention. Vaccines for Children Program (VFC): CDC Vaccine Price List. 2015.

54. Hillemanns P, Breugelmans JG, Gieseking F, Bénard S, Lamure E, Littlewood $\mathrm{KJ}$, et al. Estimation of the incidence of genital warts and the cost of illness in Germany: a cross-sectional study. BMC Infect Dis. 2008:8:76.

55. Hampl M, Huppertz E, Schulz-Holstege O, Kok P, Schmitter S. Economic burden of vulvar and vaginal intraepithelial neoplasia: retrospective cost study at a German dysplasia centre. BMC Infect Dis. 2011;11:73.

56. Jit M, Chapman R, Hughes O, Choi YH. Comparing bivalent and quadrivalent human papillomavirus vaccines: economic evaluation based on transmission model. BMJ. 2011;343:d5775.

57. Statistics Austria. Consumer price indices from 1990 to 2014. 2015.

58. Myers ER, Green S, Lipkus I. Patient preferences for health states related to HPV infection: visual analogue scales versus time trade-off elicitation. 2004

59. Gold MR, Franks P, McCoy Kl, Fryback DG. Toward consistency in cost-utility analyses: using national measures to create condition-specific values. Med Care. 1998;36:778-92.

60. Ultsch B, Damm O, Beutels P, Bilcke J, Brüggenjürgen B, Gerber-Grote A, et al. Methods for health economic evaluation of vaccines and immunization decision frameworks: a consensus framework from a European Vaccine Economics Community. Pharmacoeconomics. 2016;34(3):227-44.

61. Bruni L, Barrionuevo-Rosas L, Albero G. ICO Information Centre on HPV and Cancer (HPV Information Centre). Human Papillomavirus and Related Diseases in Austria. Summary Report. 2015.

62. Eurocare 5. Survival analysis 2000-2007. 2015. 5-3-2014.

63. UK cancer research. Cervical cancer survival statistics. 2014.

64. Sullivan PW, Slejko JF, Sculpher MJ, Ghushchyan V. Catalogue of EQ-5D scores for the United Kingdom. Med Decis Making. 2011;31:800-4.

65. Hu D, Goldie S. The economic burden of noncervical human papillomavirus disease in the United States. Am J Obstet Gynecol. 2008;198:500-7.

66. Baandrup L, Blomberg M, Dehlendorff C, Sand C, Andersen KK, Kjaer SK. Significant decrease in the incidence of genital warts in young Danish women after implementation of a National Human Papillomavirus Vaccination Program. Sex Transm Dis. 2013;40:130-5.

67. Fairley C, Hocking J, Gurrin L, Chen M, Donovan B, Bradshaw C. Continued rapid decline in warts after national quadrivalent HPV vaccine program. Montreal: IPC; 2010

68. Read TR, Hocking JS, Chen MY, Donovan B, Bradshaw CS, Fairley CK. The near disappearance of genital warts in young women 4 years after commencing a national human papillomavirus (HPV) vaccination programme. Sex Transm Infect. 2011;87:544-7. 
69. Brotherton JM, Saville AM, May CL, Chappell G, Gertig DM. Human papillomavirus vaccination is changing the epidemiology of high-grade cervical lesions in Australia. Cancer Causes Control. 2015;26:953-4.

70. Tota JE, Ramana-Kumar AV, El-Khatib Z, Franco EL. The road ahead for cervical cancer prevention and control. Curr Oncol. 2014;21:e255-64.

71. Franco EL, Mahmud SM, Tota J, Ferenczy A, Coutlée F. The expected impact of HPV vaccination on the accuracy of cervical cancer screening: the need for a paradigm change. Arch Med Res. 2009;40:478-85.

72. Huang Q, Zhong M, Gao YF, Huang LP, Huang Q, Wang W, et al. Can HPV vaccine have other health benefits more than cancer prevention? A systematic review of association between cervical HPV infection and preterm birth. J Clin Virol. 2014;61:321-8.

73. Soergel P, Makowski L, Schippert C, Staboulidou I, Hille U, Hillemanns P. The cost efficiency of HPV vaccines is significantly underestimated due to omission of conisation-associated prematurity with neonatal mortality and morbidity. Hum Vaccin Immunother. 2012;8:243-51.

74. Robert Koch Institute. Cancer in Germany 2009/2010. 9th ed. 2014.

\section{Submit your next manuscript to BioMed Central} and we will help you at every step:

- We accept pre-submission inquiries

- Our selector tool helps you to find the most relevant journal

- We provide round the clock customer support

- Convenient online submission

- Thorough peer review

- Inclusion in PubMed and all major indexing services

- Maximum visibility for your research

Submit your manuscript at www.biomedcentral.com/submit 